\title{
Price Discrimination in Two-Sided Markets
}

\author{
Kai Zhang and Weiqi Liu \\ Institute of Management and Decision, Shanxi University, Taiyuan, PR China
}

Accepted: August 2015

The use of a price discrimination strategy is an important tool in competition. It can hurt firms and benefit consumers in a one-sided market. However, in two-sided markets, its primary goal is to attract more agents or increase profits. Here, the performance of a second-degree price discrimination strategy in the context of duopoly two-sided platforms is analysed. Two exogenous variables, which include the discount rate and the price discrimination threshold, are used in order to examine whether the price discrimination strategy could help two-sided platforms achieve their objective, which is to maximise their market value. Three cases are considered, and we demonstrate that the price discrimination strategy cannot attract more agents and at the same time increase the profits; a lower price discrimination threshold cannot ensure larger markets shares; a higher discount rate is detrimental to the profit of a platform. However, this is good for its market shares. Moreover, discriminative pricing increases the competition.

Key words: price discrimination, two-sided market, cross-network externality, price discrimination threshold

JEL: C70, D43, L13

\section{$1 \quad$ Introduction}

PC operation systems, payment cards, shopping malls, electric commerce platforms, video-games, newspapers, network televisions, real estate agents, dating services and nightclubs have attracted significant attention, especially after the publication of the following seminal papers by Armstrong (2006a), Caillaud and Jullien (2003), Rochet and Tirole (2003) and Schiff (2003). In such markets, two or more unique groups of agents interact with one another via two-sided (or multi-sided) platforms. No distinction is made here between two-sided platforms and two-sided markets (Schmalensee \& Evans, 2007). The utility for an agent in one group that participates in a platform is dependent on the number of participating agents in another group in the same platform. The significant difference between two-sided markets and orthodox one-sided markets is the failure of the Coase theorem, which means that agents on both sides are unable to internalise all the externalities (Rochet \& Tirole, 2004). The fundamental problem in two-sided markets is that of how to get different groups around the platform by setting up the price structure.

A common strategy followed in two-sided markets either to attract more consumers or to increase profits is that of price discrimination, although under the Robinson-Patman Act in the United States, this is illegal in the intermediate goods markets (Liu \& Serfes, 2013). One example of this is the two-part tariff charged by Dangdang, the fifth largest Business-to-Customer in China, which is broken down as follows: the total fee per month $=$ the usage fee + the discount rate $\cdot$ trading volume. Six levels of discount rates are in place in the context of a minimum monthly sales agreement: 0 , 1.25 per cent, 1.5 per cent, 2.5 per cent, 3 per cent and 4 per cent. Five levels are in place should there be no minimum monthly sales agreement: 1.5 per cent, 2 per cent, 3 per cent, 4 per cent and 5 per cent. Another example includes the annual fee for credit cards in China - the ICBC (Industrial \& Commercial Bank of China) - BOC (Bank of China) and the ABOC (Agricultural Bank of China) all allow consumers a no annual fee for the next year based on a five-time usage during the current year, whereas the BOC (Bank of Communications) and the CMB (China Merchants Bank) base their annual fee on a six-time usage. Both the CEB (China Everbright Bank) and the CCB (China Construction Bank) base their annual fee on a three-time usage. Further examples include the local Spanish TV industry (Gil \& Riera-Crichton, 2011), broadband services and access-tiering (Weisman \& Kulick, 2010), and the B2B and B2C websites (Caillaud \& Jullien, 2003). 
Conventional wisdom dictates that to use the price discrimination strategy in one-sided markets is always detrimental to firms and beneficial to consumers (Armstrong, 2006b; Stole, 2003). However, this may not be applicable to two-sided markets (Liu \& Serfes, 2013). Previous research has demonstrated that, when the cross-group externality parameters are high enough, price discrimination leads to an increase in platform profits, hurts consumer welfare and softens competition (Liu \& Serfes, 2013). Because research into two-sided markets is still in its infancy, many unresolved issues remain: (1) whether the beneficial claim to all the agents of the price discrimination strategy in sales promotion hold true; (2) whether an increase in discount rates attracts more agents and increases profits; (3) whether the price discrimination strategy is always better than the no-price discrimination strategy; (4) how platforms correctly choose the price discrimination in order to accomplish different goals. Addressing each of these issues is the main goal of this paper.

This article expands on previous work on price discrimination in the context of two-sided markets by introducing two exogenous variables, the discount rate and a price discrimination threshold. Our analysis differs from previous work in two additional ways: first, different goals can be achieved when platforms use the price discrimination strategy, either maximising profits or maximising market shares; second, we focus on how platforms can successfully implement price discrimination in a competitive environment. Our results demonstrate that a lower price discrimination threshold does not guarantee an increase in market shares, owing to a non-monotonic function; this result accords with previous results (Liu \& Serfes, 2013). We also show that (1) a two-sided platform that uses a price discrimination strategy cannot result in both attracting more agents and increasing profits; (2) larger discount rates are bad for a platform's profit, but are good for its market shares; (3) The best response strategy for a platform aiming at maximising its profit is to retain the strategy when its opponent chooses a price discrimination strategy, otherwise this results in a smaller profit, despite the discount rates; (4) the equilibrium profits are smaller in comparison with the profits when a no-price discrimination strategy has been used. In other words, discriminative pricing increases competition.

The organization of this paper is as follows. Previous literature on two-sided markets and price discrimination is discussed in Section 2. Our assumptions and model structure are outlined in Section 3. In section 4, we present a general method of analysis and focus on three specific scenarios. Numerical examples are shown and we demonstrate a variety of applications. The main results and a discussion on the future direction of this area of research are summarized in section 5.

\section{Literature review}

\subsection{Two-sided market}

Two-sided markets, examples of which are shown in previous publications by Schmalensee and Evans (2007), Armstrong (2006a) and Rochet and Tirole (2004), received little attention, until one of the first formal analysis of two-sided business-payment cards was described by Baxter (1983). Additionally, the contributions by David (1985), Katz and Shapiro (1985) and Farrell and Saloner (1985) on network externalities have also made a significant impact on the research into two-sided markets. The first clear definition of a two-sided market was given by Rochet and Tirole (2004), in which they define a market as being two-sided if any change in the price structure or distribution is going to affect the participation level or the number of interactions on the platform, given that the total prices for both parties is held constant. Eight basic fallacies that arise from applying conventional wisdom on one-sided markets to a two-sided market setting are discussed by Wright (2004). The main characteristics of two-sided markets include cross-network externalities (Armstrong, 2006a), the winner takes all (Sun \& Tse, 2007) and the chicken and egg (Caillaud \& Jullien, 2003).

The main function of two-sided platforms is to reduce both the search and the transaction costs (Caillaud \& Jullien, 2003; Schiff, 2003), which is the same function as intermediation, by choosing 
input and output prices that will maximise profit (Spulber, 1996; Rust \& Hall, 2003; Loertscher, 2007). However, two-sided platforms and intermediates are different, the latter being more focused on traditional intermediaries, also referred to as "make the market", who buy and resell goods. The former is influenced by the rising importance of "new economy" intermediaries, who connect buyers and sellers and provide matching, price discovery, certification, advertising and other informational services, usually without assuming complete control over the transactions (Hagiu \& Jullien, 2007).

Until recently, the focus of the literature has been primarily on the effects of the relative magnitudes of indirect network externalities, demand elasticity and coordination (chicken and egg) issues in platform pricing structure. The models used in the study of two-sided markets in the current literature can be broadly categorized as a usage model, a membership model or combinations of the two. The role of fixed-membership costs and network externalities is emphasized in the usage model (e.g. Rochet \& Tirole, 2003; Chakravorti \& Roson, 2006; Guthrie and Wright, 2007). There is an emphasis on the externalities of the usage of the service in the membership model and it assumes linear (per-transaction) costs and pricing (Armstrong, 2006a; Armstrong \& Wright, 2007). Research content is another important component of two-sided models, such as multi-homing or partial multi-homing (e.g., Roson, 2005; Gabszewicz \& Wauthy, 2004; Doganoglu \& Wright, 2006), ownership (e.g., Hagiu \& Lee, 2011; Nocke \& Peitz, 2007; Rochet \& Tirole, 2003), profit or non-profit platform (e.g., Rochet \& Tirole, 2003), open and closed platform (e.g., Economides \& Katsamakas, 2006; Schiff, 2003), third-part content (Hagiu \& Spulber, 2012), dynastic competition (Chen \& Tse, 2007; Sun \& Tse, 2007; Eriksson et al., 2008) and empirical work (e.g., Kaiser \& Wright, 2005; Rysman, 2004).

\subsection{Price discrimination}

According to the seminal work of Pigou (1920), in order for price discrimination to occur in the traditional one-sided market theory, three conditions must be met: there is no re-sale between consumers, the willingness to pay varies among consumers, and there is a firm with market power that can implement price discrimination. A large body of literature on the study of both the theoretical and the empirical nature of price discrimination in a one-sided market exists. However, the focus here is on the price discrimination in a two-sided market.

The development of the Internet and the rapid growth of sophisticated software tools are the two main reasons for the increasing adoption of the price discrimination as a common strategy, as mentioned by Liu and Serfes (2013). Nevertheless, little research has been conducted on the price discrimination strategy and competition in the context of a two-sided market. The effect of group-specific prices, i.e. third degree price discrimination, has been analyzed by Caillaud and Jullien (2003) and Armstrong (2006), while two-part tariffs were analyzed by Roche and Tirole (2003), Armstrong (2006a) and Reisinger (2014). First-degree price discrimination in a duopolistic two-sided market was examined by Liu and Serfes (2013). There are few similarities between the study by Liu and Serfes (2013) and our study, but there are three main differences.

First, we study second-degree price discrimination. Agents on each side are charged differential prices according to the transaction time. This means that agents within a certain range have the same entrance price, which is more realistic owing to the difficulty of first-degree price discrimination. Second, unlike the study by Liu and Serfes (2013), in which they focus exclusively on the equilibrium price, our study considers our model's important role price in discount rates and discrimination thresholds. Third, the model by Liu and Serfes (2013) focuses on the profitability and welfare implication of price discrimination, whereas our model concentrates on the successful implementation of price discrimination in different cases. Gil and Riera-Crichton (2011) expand upon the model and results by Liu and Serfes (2013) through the addition of a simple extension for the monopoly case with no competition because of very high transportation costs. However, the main goal of their study was to revisit the empirical relation between price discrimination and competition in the Spanish local television sector and to show that price discrimination negatively 
correlates with the degree of product market competition. A study carried out by Weisman and Kulick (2010), which was based on the Notice of Proposed Rulemaking (NPRM) released by the Federal Communications Commission (FCC), indicated that price discrimination is likely to increase the static efficiency in the market for broadband services, because the market is two-sided and that it also promotes dynamic efficiency because it encourages innovation in the provision of broadband services. Several possible price discrimination strategies that may become available if network neutrality is abolished are presented by Economides (2008).

In summary, the intuitively significant features of price discrimination in two-sided markets is not fully explained in the current literature, owing to the focus on the competition and consumer's welfare while neglecting the implementation of strategy. To gain insight into the new mechanism of price discrimination in two-sided markets, we consider the discount rate in the normal model and use transaction times as the price discrimination threshold. Further, by incorporating different goals of platforms, we present a general analysis method and compare the three special scenarios on price discrimination.

\section{The model}

The basis of our model is similar to that of the model found in Armstrong (2006a). We assume that there are duopolistic two-sided platforms that offer horizontal differentiated products, including platforms like newspapers, credit cards, shopping centers, night clubs, and e-commences. Two platforms, denoted by $k(k=1,2)$ are located at the two end points of the unit interval [0,1], with platform 1 located at 0 and platform 2 at 1 . Each platform deals with two distinct groups of agents, denoted by $i(i=A, B)$, and each agent is assumed to make transactions on only one platform. In other words, each agent in both groups is single-homing. The potential gains from trade, that is, profits for the platforms and the utilities for agents, are created through the transaction between distinct two-sided agents. Agents are charged because we assume that platforms are profit-making organizations with their goal of profit maximisation. The fixed and marginal costs per agent served are normalized to zero. The number of agents in one group of the platform is dependent on the number of agents in the opposite group who participate in the same platform, as is shown in Rochet and Tirole (2006) and Armstrong (2006a). Agents in both groups are normalized to one and uniformly distributed on $[0,1]$. An assumption made is that each agent on both sides is able to choose a multi-time transaction, which is the basis of the price discrimination strategy. The utility of agent $i$ located at $x$ in platform $k$ is given by

$$
u_{k i}=v_{i}-p_{k i}-t_{i} x+\theta_{i} q_{k j}, \quad k=1,2 \text { and } i, j=A, B \text { and } i \neq j
$$

where $v_{i}$ represents the stand-alone benefits, also referred to as the basic benefits, that agent $i$ receives, which is independent of the number of agents on platform $k ; q_{k j}$ represents the actual number of agents $j$ who are present on platform $k ; t_{i}$ represents the product differentiation parameters, also referred to as the transport costs; $\theta_{i}$ is the cross-network externality, which is the benefit that agent $i$ receives from the transaction with each agent $j ; p_{k i}$ is the platform $k$ 's real lump-sum charge to agent $i$.

In order to address the chicken and egg problem and to obtain a competitive advantage, each platform can choose a price discrimination strategy according to the real transaction times of each agent $\left(n_{k i}\right)$. Additionally, we assume that price discrimination thresholds $\left(N_{k i}\right)$ are exogenous. If $n_{k i}<$ $N_{k i}$, agent $i$ will be charged a benchmark price $\left(P_{k i}\right)$ by platform $k$; or if $n_{k i} \geq N_{k i}$, agent $i$ will be charged a discount price $\left(p_{k i}\right)$ by platform $k$. For simplification and visualization purposes, suppose that $p_{k i}=\left(1-d_{k i}\right) P_{k i}$, where $0 \leq d_{k i} \leq 1$ is the discount rate. Specifically, $d_{k i}=1$ implies a free charge strategy for agent $i$, who participates in platform $k ; d_{k i}=0$ indicates that there is no price discrimination and the benchmark price is the discount price. If agents on both sides have a price discrimination strategy imposed, the results will become vague and complicated, so the assumption is made that only agent $A$ encounters the price discrimination executed by the platforms and that 
agent $B$ can always guarantee the demand coming from agent $A$, despite the number of transaction times.

To further simplify the results, the following assumptions were also made 1) $v_{i}$ is high enough so that the agents' markets are completely covered. This would ensure that platforms were not a local monopoly and would compete for the two groups of agents under the standard Hotelling model conditions. 2) $t_{i}>\theta_{i}$. This assumption implies that production differentiation is stronger than average across network externality, despite being within groups or across groups (Armstrong, 2006a). This would also rule out the possibility of corner solutions, which occur when all the agents choose the same platform independently of their location. For saving variables, let $t_{A}=t_{B}=t$ and $\theta_{A}=\theta_{B}=\theta$. 3) $N_{1}>N_{2}$. There are three cases $N_{1 A}>N_{2 A}, N_{1 A}<N_{2 A}$, and $N_{1 A}=N_{2 A}$, given that the two platforms make their own price discrimination threshold both independently and at the same time. $N_{1 A}=N_{2 A}$ is a special situation of the other two cases, and $N_{1 A}>N_{2 A}$ is the same as $N_{1 A}<N_{2 A}$ owing to the symmetric assumption previously mentioned, which is that there is no fixed cost and no marginal cost. Thus, $N_{1 A}>N_{2 A}$ is a typical case found in this model and can be simplified to $N_{1}>N_{2}$. 4) Both platforms and agents pursue short-term profits or utilities, which implies that every platform maximises profits from the sum of every transaction and no agent is given a special preference on either platform.

The game process unfolds as described: in stage 0 , both platforms choose a price discrimination strategy to overcome the chicken and egg problem; in stage 1, both platforms 1 and 2 simultaneously decide their benchmark prices, given that both the discount rate and the price discrimination threshold are exogenous; in stage 2, agents choose either platform 1 or platform 2 in accordance with the principle of maximum utility.

\section{The analysis}

Each agent in both groups observes all the entrance prices before deciding which platform to join. The number of agents who join a platform is given by the Hotelling specification (Caillaud \& Jullien, 2003; Armstrong, 2006a). The location of the marginal agent $i$, who is indifferent to the choice between platforms 1 and 2 , is given by $u_{1 i}\left(p_{1 i}, x, q_{1 j}\right)=u_{2 i}\left(p_{i 2}, 1-x, q_{2 j}\right)$, in which $x$ is the distance between marginal agent $i$ and platform 1, and is also referred to as the actual number of agents who choose platform 1 , until it can be seen that the adjustment will continue until the marginal agent $i$ receives the same utility in both platforms. Given that the platforms set different price thresholds, the following should be satisfied when equilibrium is reached:

$$
\left\{\begin{array}{l}
u_{1 A}\left(P_{1 A}, q_{1 A}^{N N}, q_{1 B}\right)=u_{2 A}\left(P_{2 A}, 1-q_{2 A}^{N N}, q_{2 B}\right) \\
u_{1 A}\left(P_{1 A}, q_{1 A}^{N D}, q_{1 B}\right)=u_{2 A}\left(p_{2 A}, 1-q_{2 A}^{N D}, q_{2 B}\right) \\
u_{1 A}\left(p_{1 A}, q_{1 A}^{D D}, q_{1 B}\right)=u_{2 A}\left(p_{2 A}, 1-q_{2 A}^{D D}, q_{2 B}\right) \\
u_{1 B}\left(P_{1 B}, q_{1 B}, q_{1 A}\right)=u_{2 A}\left(P_{2 B}, 1-q_{1 B}, q_{2 A}\right)
\end{array}\right.
$$

where $q_{k A}^{N N}, q_{k A}^{N D}, q_{k A}^{D D}$ is the demand of agent $A$, who participates in platform $k$ when $n_{k A}<N_{2}$, $N_{2}<n_{k A}<N_{1}, n_{k A}>N_{1}$, respectively.

The total demand of agent $A$ participating in platform $k$ will then be

$$
q_{k A}=\alpha q_{k A}^{N N}+\beta q_{k A}^{N D}+\gamma q_{k A}^{D D}
$$

where $\alpha, \beta, \gamma$ is the uniform probability destiny of agent $A$ when $n_{k A}<N_{2}, N_{2}<n_{k A}<N_{1}, n_{k A}>N_{1}$ and also satisfies $\alpha+\beta+\gamma=1$. In other words, $\alpha$ represents the scenario in which there is no price discrimination being imposed on agent $A$ by the two platforms; $\beta$ represents the scenario in which only a price discrimination from platform 2 and no price discrimination from platform 1 is being imposed on agent $A ; \gamma$ represents the scenario in which both platforms are simultaneously imposing price discrimination on agent $A$. A larger $N_{2}$ means a bigger $\alpha$, resulting in a smaller number of agent $A$ s that will enjoy a price discrimination strategy made by both platforms; a larger threshold gap $N_{1}-N_{2}$ means a bigger $\beta$, resulting in an increase in the difference between the two platforms; a larger 
$N_{1}$ means a smaller $\gamma$, resulting in fewer agent $A$ s who will face a price discrimination strategy imposed by platform 1 .

The profit functions of platforms 1 and 2 respectively are given by,

$$
\left\{\begin{array}{l}
\pi_{1}=P_{1 A} \alpha q_{1 A}^{N N}+P_{1 A} \beta q_{1 A}^{N D}+p_{1 A} \gamma q_{1 A}^{D D}+P_{1 B} q_{1 B} \\
\pi_{2}=P_{2 A} \alpha q_{2 A}^{N N}+p_{2 A} \beta q_{2 A}^{N D}+p_{2 A} \gamma q_{2 A}^{D D}+P_{2 B} q_{2 B}
\end{array}\right.
$$

In order to derive the optimal entrance prices for each platform, we substitute (2) into the profit functions (3) and consider the first partial derivative of $\pi_{k}$ with respect to $P_{k i}$. The high number of variables leads to extremely complex results, so here we attempt to study the impact of the price discrimination strategy executed by two-sided platforms from three special scenarios based on the previously described framework.

\subsection{Scenario $1: \alpha=0$}

In this scenario, when $\alpha=0$ this indicates that $\beta+\gamma=1$, that is, platform 2 executes a price discrimination strategy on each agent $A$, while platform 1 aims at only a partial agent $A$, whose transaction time exceeds the price discrimination threshold $N_{1}$. The main research question being addressed here is to determine the effectiveness of the price discrimination strategy in benefiting all the agents.

Proposition1. Given $\alpha=0$, the equilibrium benchmark prices for each group of agents made by platform $k$ are:

$$
\begin{array}{cc}
P_{1 A}=(t-\theta) \frac{3\left(1-\gamma d_{1}\right)}{\Delta} & P_{1 B}=(t-\theta)\left(1+\frac{4 \beta \gamma d_{1}^{2} \theta}{t \Delta}\right) \\
P_{2 A}=\frac{(t-\theta)}{1-d_{2}}\left(1-\frac{2 \beta \gamma d_{1}^{2}}{\Delta}\right) & P_{2 B}=(t-\theta)\left(1+\frac{2 \beta \gamma d_{1}^{2} \theta}{t \Delta}\right)
\end{array}
$$

the equilibrium market shares are:

$$
\begin{array}{ll}
q_{1 A}=\frac{1}{2}+\frac{\beta \gamma d_{1}^{2}(t-\theta)}{t \Delta} & q_{1 B}=\frac{1}{2} \\
q_{2 A}=\frac{1}{2}-\frac{\beta \gamma d_{1}^{2}(t-\theta)}{t \Delta} & q_{2 B}=\frac{1}{2}
\end{array}
$$

and the equilibrium profit of each platform is:

$$
\pi_{1}=(t-\theta)\left[1-\frac{\beta \gamma d_{1}^{2}\left(5 \Delta-4 \beta \gamma d_{1}^{2}\right)(t-\theta)}{2 t \Delta^{2}}\right] \quad \pi_{2}=(t-\theta)\left[1-\frac{\beta \gamma d_{1}^{2}\left(4 \Delta-4 \beta \gamma d_{1}^{2}\right)(t-\theta)}{2 t \Delta^{2}}\right]
$$

where $\Delta=3\left(1-\gamma d_{1}\right)^{2}+4 \gamma \beta d_{1}^{2}$.

From proposition 1, the following observation can be made:

1) $P_{2 A}$ is increasing with $d_{2}$, while the other equilibrium benchmark prices, $P_{1 A}$ and $P_{k B}$, are completely independent of $d_{2}$, as are the equilibrium market shares and profits.

2) $\quad P_{1 B}>P_{2 B}$ and $P_{1 A}>p_{2 A}>p_{1 A}$, but the relation between $P_{1 A}$ and $P_{2 A}$ is unclear.

3) Despite the relation between $d_{1}$ and $d_{2}$, we obtain $q_{1 A}>q_{2 A}$ and $q_{1 B}=q_{2 B}$.

4) $\pi_{2}>\pi_{1}$ and $q_{1 A}>q_{2 A}$.

\section{Proof 2)}

$$
P_{1 A}-p_{2 A}=\frac{\gamma d_{1}\left(3+d_{1} \beta-3 d_{1}\right)(t-\theta)}{\Delta}>0 \text { and } p_{2 A}-p_{1 A}=\frac{\beta d_{1}\left(3+d_{1} \beta-d_{1}\right)(t-\theta)}{\Delta}>0 \text {. }
$$

The interpretation of the price discrimination strategy is straightforward: $d_{1}$ plays an important role in $P_{k i}, q_{k A}$ and $\pi_{k}$, as shown in equations (4), (5) and (6). In a sense, the first observation that the price discrimination strategy as executed by platform 2 is a fraudulent act is intuitive, because, as platform 
2, with a discount rate of $d_{2}$, increases, the benchmark price up to $P_{2 A} /\left(1-d_{2}\right)$ eventually results in agent $A$ being charged the same actual price as if there were no price discrimination. In addition, the conclusion can be drawn that a full price discrimination strategy should not be trusted by any agent $A$, resulting in the failure of platform 2 to attract more agents, as shown in the first part of observation 3. The second observation implies that, despite what the price discrimination thresholds and discount rates are, in comparison with platform 2, platform 1 will always make a higher benchmark equilibrium price for agent $B$; the discriminatory price charged to agent $A$ by platform 2 is higher than that in platform 1 , but it is lower than the benchmark equilibrium price of platform 1 . This also demonstrates that platform 2, with a full price discrimination strategy, is performing fraudulent behavior. The third observation indicates that the price discrimination strategy works only on agent $A$ 's market shares and has no effect on agent $B$ 's. Platform 1 obtains more agent $A$ s than does platform 2. However, agent $B$ 's market is divided equally. The fourth observation is typically expected. That is, the full price discrimination strategy is better than the partial price discrimination strategy from the view of a two-sided platform; this is owing to $P_{2 A}$ being the dominant variable and more important than $P_{2 B}, q_{2 A}$ and $q_{2 B}$. This could potentially explain why the full price discrimination strategy is common practice and why so many companies always declare that anyone who participates in them will enjoy a promotion price. Ironically, this is a mere illusion.

Especially, if $d_{1}=d_{2}=0$, then no price discrimination is imposed, the equilibrium results are $P_{k i}=t-\theta$ and $q_{k i}=0.5$ and $\pi_{k}=t-\theta$. This conclusion is the same as the conclusions drawn by Armstrong (2006a) and Rochet and Tirole (2004). Equilibrium prices depend in a positive way on the differentiation parameter $t$ and negatively on the strength of the cross-network externality $\theta$, while the agent's market shares and platform's profit are divided equally.

Corollary1. Based on Proposition 1, the following is true:

1) $q_{2 \beta A}>q_{1 \beta A}$ and $q_{2 \gamma A}<q_{1 \gamma A}$.

5) $\pi_{2 A}>\pi_{1 A}$ and $\pi_{2 B}<\pi_{1 B}$.

6) If $\gamma\left(1-d_{1}\right)>\beta, \pi_{1}$ and $\pi_{2}$ decreases with $\beta$ while $\left(\pi_{2}-\pi_{1}\right)$ increases with $\beta$.

7) $\pi_{1}$ and $\pi_{2}$ represent the decreasing function of $d_{1}$, whereas $\left(\pi_{2}-\pi_{1}\right)$ represents the increasing function of $d_{1}$.

Proof. Owing to the complex nature of the initial expression of the results, the details of the expression of $q_{k \beta A}, q_{k \gamma A}, \pi_{k i}$ are omitted and only the comparison results are shown. The conclusion from Corollary 1 can easily be drawn from the following results.

$$
\begin{aligned}
& q_{1 \beta A}-q_{2 \beta A}=-\frac{\beta \gamma d_{1}\left(3+\beta d_{1}-3 d_{1}\right)(t-\theta)}{t \Delta}<0, \quad q_{1 \gamma A}-q_{2 \gamma A}=\frac{\beta \gamma d_{1}\left(3+\beta d_{1}-d_{1}\right)(t-\theta)}{t \Delta}>0 \\
& \pi_{2 A}-\pi_{1 A}=-\frac{\gamma \beta d_{1}^{2}\left(t^{2}-\theta^{2}\right)}{2 t \Delta}<0, \pi_{2 B}-\pi_{1 B}=\frac{\gamma \beta \theta d_{1}^{2}(t-\theta)}{2 t \Delta}<0, \\
& \text { and } \pi_{2}-\pi_{1}=\frac{\gamma \beta d_{1}^{2}(t-\theta)^{2}}{2 t \Delta}>0 .
\end{aligned}
$$

The first result shows that more agent $A$ s choose platform 1 when they face a discriminatory price imposed simultaneously by the two platforms. Combining this result with Proposition 1(3), we can conclude that platform 1 should set a discriminatory price if platform 2 chooses a full price discrimination strategy. This is because platform 1 attracts more agent $A$ s, both in target agent $A$ s and total agent $A$ s than does platform 2. The second result shows that platform 2 receives more profits from agent $B$ 's market, but fewer profits from agent $A$ 's market. The third result implies that platform 2 has a competitive advantage. Given a fixed discount rate and $\beta<\left(1-d_{1}\right) /\left(2-d_{1}\right)$, the larger $\beta$ means a larger $N_{1}$, which is bad for both of the two platforms. However, it is worse for platform 1. The disadvantageous position of platform 1 in this situation improves, but its profit is still less than that of platform 2. This implies that platform 1 should set a high price discrimination threshold when platform 2 chooses a full price discrimination strategy, given a fixed discount rate. The first part of the fourth result is similar to a commonly drawn conclusion for a one-sided market, 
that is, that price discrimination transfers the partial platform's profit to the consumers. The second part of the fourth result implies that a larger $d_{1}$ puts platform 1 at a disadvantage against platform 2 , which is the same as the third result. Therefore, choosing a smaller $d_{1}$ is an optimal strategy for platform 1 when its competitor chooses to implement a full price discrimination strategy.

The comparative statistics for the parameters of $\beta$ and $d_{1}$ and the other equilibrium variables are presented in Table 1.

Table 1

Comparative statistics for the scenario where $\alpha=0$

\begin{tabular}{|c|c|c|c|c|c|c|c|c|c|c|c|c|}
\hline & \multicolumn{6}{|c|}{$P$} & \multicolumn{6}{|c|}{$q$} \\
\hline & \multicolumn{3}{|c|}{ Platform 1} & \multicolumn{3}{|c|}{ Platform 2} & \multicolumn{3}{|c|}{ Platform 1} & \multicolumn{3}{|c|}{ Platform 2} \\
\hline & $P_{1 A}$ & $p_{1 A}$ & $P_{1 B}$ & $P_{2 A}$ & $p_{2 A}$ & $P_{2 B}$ & $q_{1 \beta A}$ & $q_{1 \gamma A}$ & $q_{1 A}$ & $q_{2 \beta A}$ & $q_{2 \gamma A}$ & $q_{2 A}$ \\
\hline$\beta$ & $\uparrow^{\star *}$ & $\uparrow^{\star *}$ & $\uparrow^{*}$ & $\downarrow^{*}$ & $\downarrow^{*}$ & $\uparrow^{*}$ & $\uparrow$ & $\downarrow$ & $\uparrow^{*}$ & $\downarrow$ & $\uparrow$ & $\downarrow^{*}$ \\
\hline$d_{1}$ & $\uparrow^{* * *}$ & $\downarrow$ & $\uparrow$ & $\downarrow$ & $\downarrow$ & $\uparrow$ & $\uparrow^{* * * *}$ & $\uparrow$ & $\uparrow$ & $\downarrow^{* * * *}$ & $\downarrow$ & $\downarrow$ \\
\hline
\end{tabular}

Note: $\downarrow$ decrease; $\uparrow$ increase;

${ }^{\star} \gamma\left(1-d_{1}\right)>\beta ;{ }^{* \star}\left(1-r d_{1}\right)^{2}>4\left(1-d_{1}\right) ;{ }^{* \star *} \Delta>8 \beta d_{1} ; ;^{* \star \star *} 3\left(1-\gamma d_{1}\right)^{2}<4 \beta d_{1}$

Here, a numerical example is given in order to show other detailed findings not displayed in Proposition 1 and Corollary 1. Let $t=1.2, \theta=0.5$ and $d_{2}=0.3$, and the illusive results are shown in Figure 1.

The comparative statistics of the equilibrium prices with respect to $\beta$ and $d_{1}$ are shown in Figure 1 (a) and Figure 1 (d) and the following observation can be made. First, $P_{1 A}$ and $p_{1 A}$ decrease in $\beta$ when $\beta<0.87$ and increase in $\beta$ when $\beta>0.87 ; P_{1 A}$ decreases in $d_{1}$ when $d_{1}>0.5$ and increases in $d_{1}$ when $d_{1}<0.5$; the rest of the variables are in accordance with Table 1 . Second, $p_{2 A}-p_{1 A}$ increases in $\beta$, but $P_{2 A}-P_{1 A}$ only increases in $\beta$ if $\beta>0.19$ and decreases in $\beta$ if $\beta<0.19$. Third, despite the value of $\beta$ and $d_{1}$, discriminative prices are lower than the equilibrium prices when there is no price discrimination.

The comparative statistics for the equilibrium market shares of platform 1 in agent $A$ 's market with respect to $\beta$ and $d_{1}$ are shown in Figure 1 (b) and Figure 1 (e), and we observe that $q_{1 A}$ increases in $\beta$ if $\beta<0.375$ and decreases in $\beta$ if $\beta>0.375 ; q_{1 \beta A}$ increases in $d_{1}$ if $d_{1}<0.67$ and increases in $d_{1}$ if $d_{1}>0.67$; the rest of the variables are also consistent with our findings for Proposition 1, Corollary 1 and Table 1. The market shares figures for platform 2 are ignored because they are the reverse of those shown in Figure 1 (b) and Figure 1 (e) for platform 1. 
Figure 1

Impacts of $\beta$ (when $d_{1}=0.4$ ) or $d_{1}$ (when $\beta=0.4$ ) on equilibrium prices, market shares and profits

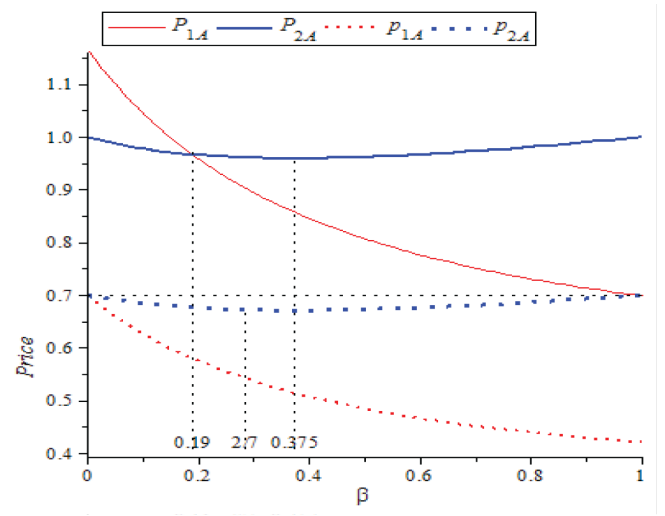

(a) Impact of $\beta$ on equilibrium prices $\left(d_{1}=0.4\right)$

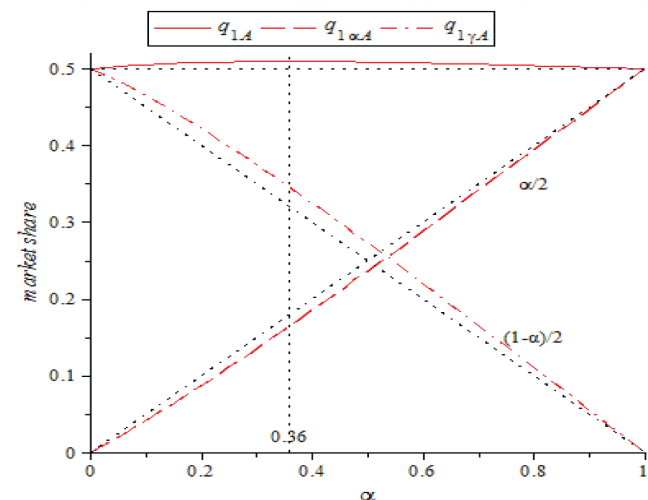

(b) Impact of $\beta$ on market shares $\left(d_{1}=0.4\right)$

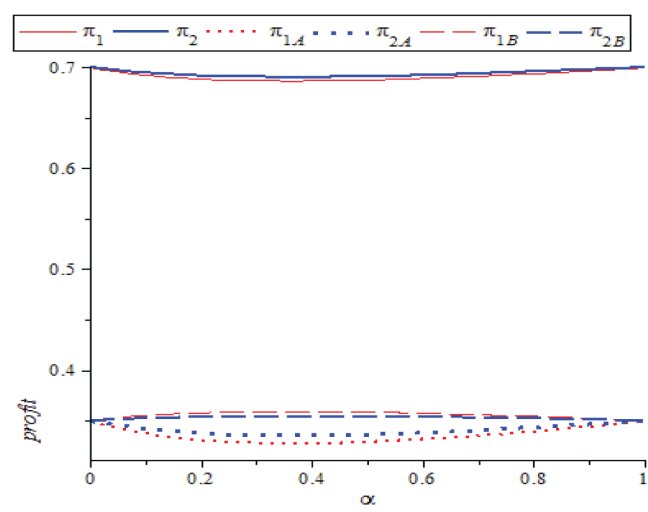

(c) Impact of $\beta$ on profits $\left(d_{1}=0.4\right)$

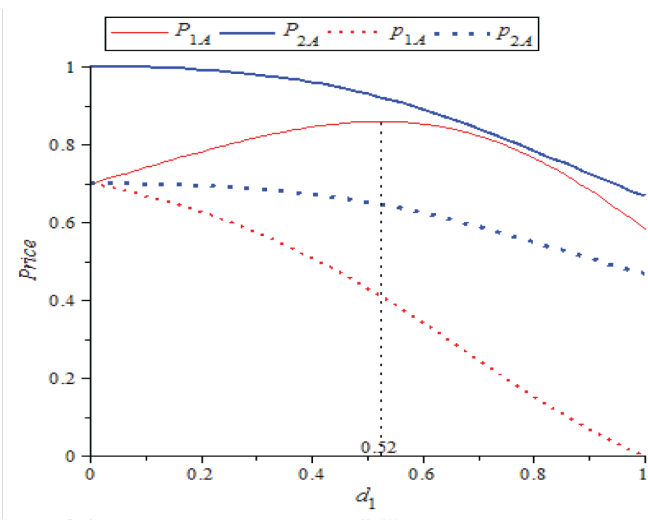

(d) Impact of $d_{1}$ on equilibrium prices $(\beta=0.4)$

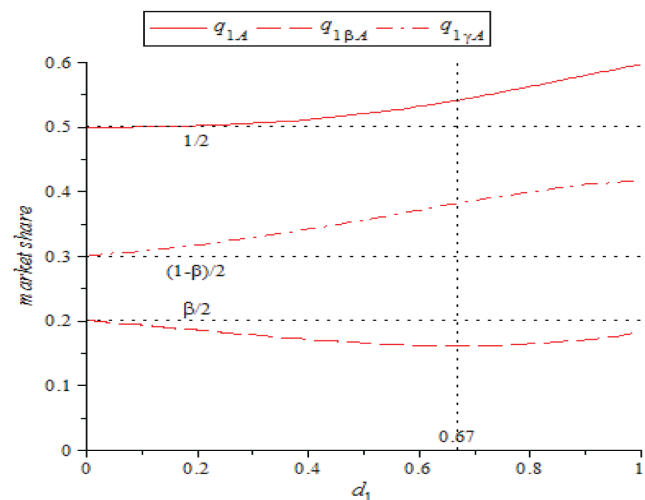

(e) Impact of $d_{1}$ on market share $(\beta=0.4)$

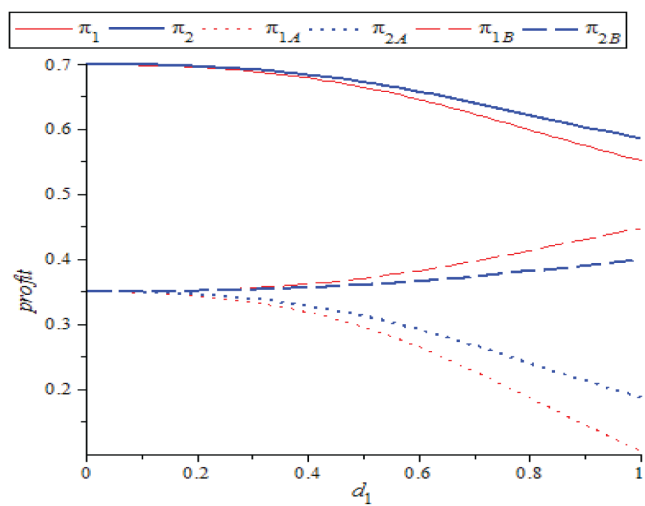

(f) Impact of $d_{1}$ on profits $(\beta=0.4)$

\subsection{Scenario $2: \beta=0$}

In this scenario, when $\beta=0$ it indicates that $\alpha+\gamma=1$, that is, platforms 1 and 2 have set the same price discrimination threshold and compete for a part of agent $A$, whose transaction time exceeds the watershed. The only difference between the platforms is the discount rate. The main question being addressed is whether or not a high discount rate can attract more agents and increase profits. A larger number of independent variables lead to complex results, so Proposition 2 provides only the difference of the relative variables shown below: 
Proposition2. Given $\beta=0$, the difference between the benchmark equilibrium prices of the two platforms are:

$$
\begin{aligned}
& P_{1 A}-P_{2 A}=\gamma\left(d_{1}-d_{2}\right)\left[(3-\alpha)\left(1-d_{1}\right)\left(1-d_{2}\right)+\alpha\left(1-2 d_{1} d_{2}\right)\right] \frac{(t-\theta)}{\Gamma} \\
& p_{1 A}-p_{2 A}=-\alpha\left(d_{1}-d_{2}\right)\left[3-\gamma\left(d_{1}+d_{2}+d_{1} d_{2}\right)\right] \frac{(t-\theta)}{\Gamma} \\
& P_{1 B}-P_{2 B}=2 \alpha \gamma\left(d_{1}-d_{2}\right) \frac{\Omega\left(t \theta-\theta^{2}\right)}{t \Gamma}
\end{aligned}
$$

the difference in the equilibrium market shares are:

$$
\begin{aligned}
& q_{1 A}-q_{2 A}=2 \alpha \gamma\left(d_{1}-d_{2}\right) \frac{\Omega(t-\theta)}{t \Gamma} \quad q_{1 B}-q_{2 B}=0 \\
& q_{1 \alpha A}-q_{2 \alpha A}=-\frac{\alpha}{t}\left(P_{1 A}-P_{2 A}\right) \quad q_{1 \gamma A}-q_{2 \gamma A}=-\frac{\gamma}{t}\left(p_{1 A}-p_{2 A}\right)
\end{aligned}
$$

and the differences in the profits between two platforms are:

$$
\begin{aligned}
& \pi_{1 A}-\pi_{2 A}=-\alpha \gamma\left(d_{1}-d_{2}\right) \frac{\Omega\left(t^{2}-\theta^{2}\right)}{2 t \Gamma} \pi_{1 B}-\pi_{2 B}=\alpha \gamma\left(d_{1}-d_{2}\right) \frac{\Omega\left(t \theta-\theta^{2}\right)}{t \Gamma} \\
& \pi_{1}-\pi_{2}=-\alpha \gamma\left(d_{1}-d_{2}\right) \frac{\Omega(t-\theta)^{2}}{2 t \Gamma}
\end{aligned}
$$

where $\Omega=d_{1}+d_{2}-2 \gamma d_{1} d_{2}>0$ and $\Gamma=4 \alpha \lambda\left(d_{1}-d_{2}\right)^{2}+3\left[\alpha+\gamma\left(1-d_{1}\right)\left(1-d_{2}\right)\right]^{2}>0$.

The following observations can be drawn from Proposition 2 :

8) The relation between $P_{1 A}$ and $P_{2 A}$ is dependent on $d_{1}$ and $d_{2}$, as are $\alpha$, and $q_{1 \alpha A}$ and $q_{2 \alpha A}$. ell.

9) Despite the relation between $d_{1}$ and $d_{2}, q_{1 B}=q_{2 B}$.

10) $p_{1 A}<p_{2 A}, P_{1 B}>P_{2 B}, q_{1 A}>q_{2 A}, q_{1 \gamma A}>q_{2 \gamma A}, \pi_{1 A}<\pi_{2 A}, \pi_{1 B}>\pi_{2 B}$ and $\pi_{1}<\pi_{2}$ if $d_{1}>d_{2}$.

The first observation implies that a larger price discount cannot ensure a larger benchmark equilibrium price in agent $A$ 's market, because $\alpha$ also plays an important role in equilibrium. $P_{1 A}>P_{2 A}$ is satisfied if $(3-\alpha)\left(1-d_{1}\right)\left(1-d_{2}\right)+\alpha\left(1-2 d_{1} d_{2}\right)>0$ and $d_{1}>d_{2} . q_{1 \alpha A}$ and $q_{2 \alpha A}$ also have a similar result. The second observation shows that two platforms also equally share agent $B$ 's market, as in scenario 1 , where $\alpha=0$. The third observation indicates that platform 1 , when it has a higher discount rate, can attract more agents $A$ and receive a higher price and an increase in the profit from agent $B$ 's markets. However, it receives far less profit from agent $A$ 's market compared with the total profits from platform 2. That is, a platform with a higher discount rate attracts only more participating agents. Thus, a platform can extend its market share by setting a higher discount rate when its opponent also chooses to use a price discrimination strategy. Additionally, the third observation proves that a larger discount rate leads to a smaller discriminative price, which is in accordance with the real phenomenon found in reality.

If $d_{1}=d_{2}$, i.e., then two platforms set the same discount rates and we have the following:

$$
\begin{array}{ll}
P_{1 A}=P_{2 A}=\frac{\left(1-\gamma d_{1}\right)}{\gamma\left(1-d_{1}\right)^{2}+\alpha}(t-\theta) & P_{1 B}=P_{2 B}=\left(1+\frac{\alpha \gamma \theta d_{1}^{2}}{t\left[\gamma\left(1-d_{1}\right)^{2}+\alpha\right]}\right)(t-\theta) \\
p_{1 A}=p_{2 A}=\frac{\left(1-\gamma d_{1}\right)\left(1-d_{1}\right)}{\gamma\left(1-d_{1}\right)^{2}+\alpha}(t-\theta) & \pi_{1}=\pi_{2}=\left(1-\frac{\alpha \gamma d_{1}^{2}(t-\theta)}{2 t\left[\gamma\left(1-d_{1}\right)^{2}+\alpha\right]}\right)(t-\theta)
\end{array}
$$

We get $P_{k A}>t-\theta, P_{k B}>t-\theta, p_{k A}<t-\theta, q_{k i}=0.5$ and $\pi_{k}<t-\theta$. Both platforms set higher benchmark prices, but obtain fewer profits. The only winner is the partial of agent $A$, whose transaction times exceed the threshold because they can enjoy a low discriminative price. In other words, a price discrimination strategy is a complete failure in this situation in comparison with the situation where there is no price discrimination. 
The same numerical example is given to show some other detailed findings: $t=1.2$ and $\theta=0.5$, and the illusive results are shown in Figure 2. The analyses of the comparative statistics of the variables with respect to $d_{2}$ were omitted owing to the symmetric structure in this scenario.

\section{Figure 2}

Impacts of $\alpha$ (when $d_{1}=0.4 ; d_{2}=0.2$ ) or $d_{1}$ (with $\alpha=0.4$ and $d_{2}=0.4$ ) on equilibrium prices, market shares and profits

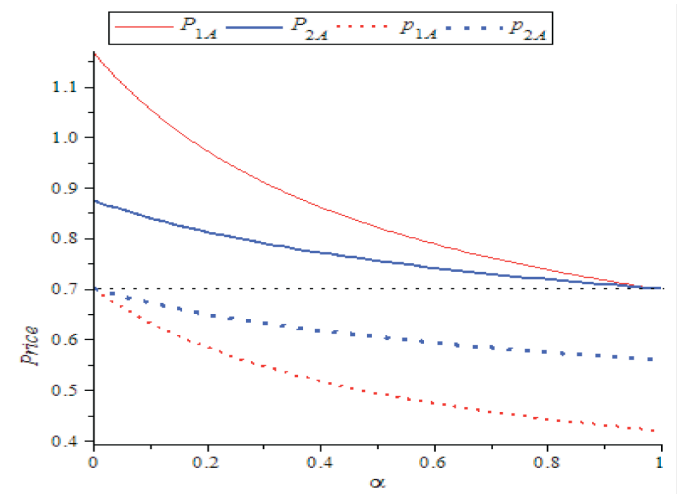

(a) Impact of $\alpha$ on equilibrium prices $\left(d_{1}=0.4 ; d_{2}=0.2\right)$

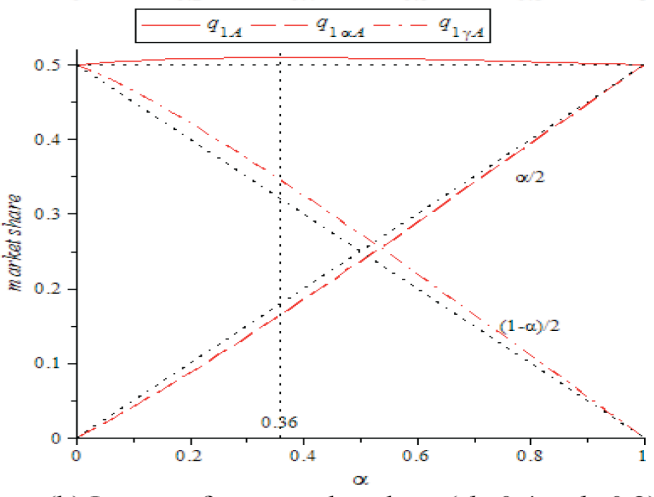

(b) Impact of $\alpha$ on market share $\left(d_{1}=0.4 ; d_{2}=0.2\right)$

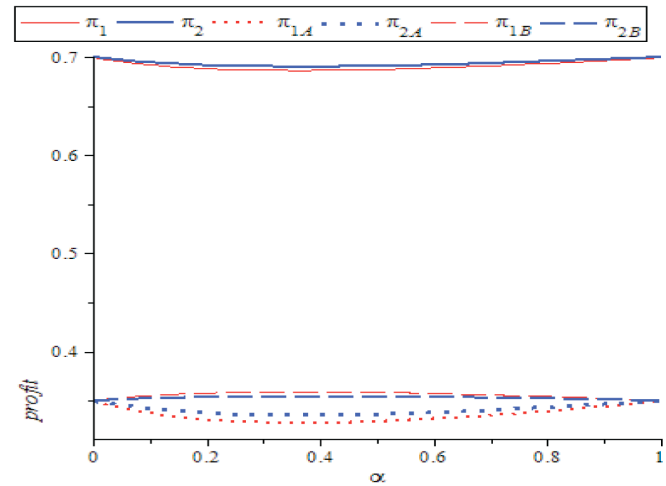

(c) Impact of $\alpha$ on profits $\left(d_{1}=0.4 ; d_{2}=0.2\right)$

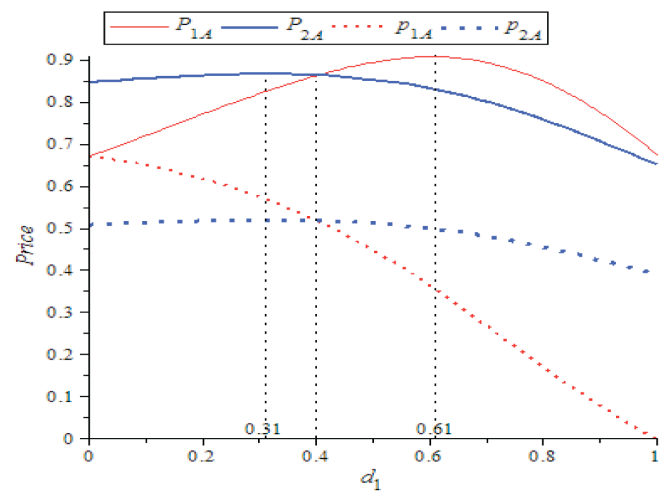

(d) Impact of $d_{1}$ on equilibrium prices $\left(\alpha=0.4 ; d_{2}=0.2\right)$

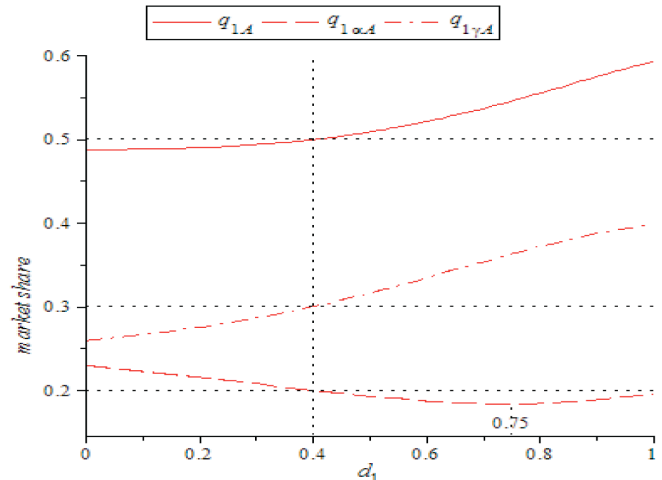

(e) Impact of $d_{1}$ on market share $\left(\alpha=0.4 ; d_{2}=0.2\right)$

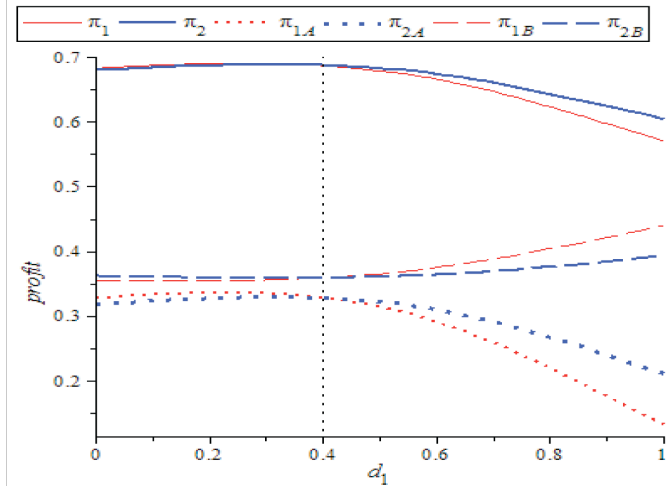

(f) Impact of $d_{1}$ on profits ( $\left.\alpha=0.4 ; d_{2}=0.2\right)$

The comparative statistics of the equilibrium prices with respect to $\alpha$ and $d_{1}$ are shown in Figure 2 (a) and Figure 2 (d), and several observations are noted. First, both $P_{k A}$ and $p_{k A}$ decrease in $\alpha$ when $d_{1}>d_{2}$, but they increase and then decrease following an increase of $d_{1}$. Second, $P_{1 A}-P_{2 A}$ decreases in $\alpha$ while $p_{2 A}-p_{1 A}$ increases in $\alpha$ if $d_{1}>d_{2} ; P_{2 A}-P_{1 A}$ and $p_{2 A}-p_{1 A}$ decrease in $d_{1}$ if $d_{1}<d_{2} ; p_{2 A}-p_{1 A}$ is increasing in $d_{1}$ if $d_{1}>d_{2}$, but $P_{2 A}-P_{1 A}$ first increase in $d_{1}$ and then decrease in $d_{1}$ if $d_{1}>d_{2}$; third, 
despite the value of $\alpha, P_{k A}>t-\theta$ and $p_{k A}<t-\theta$. However, the same observation in Figure 2 (d) cannot be obtained.

The comparative statistics of the equilibrium market shares of platform 1 in agent $A$ 's market with respect to $\alpha$ and $d_{1}$ are shown in Figure 2 (b) and Figure $2(\mathrm{e})$, and we observe that $q_{1 A}$ is increasing in $\alpha$ if $\alpha<0.36$ and increasing in $\alpha$ if $\alpha>0.36 ; q_{1 \alpha A}$ increases in $\alpha$, but $q_{1 \gamma A}$ decreases in $\alpha$; $q_{1 A}$ and $q_{1 \gamma A}$ increase in $d_{1}$, but $q_{1 \alpha A}$ decreases in $d_{1}$ if $d_{1}<0.75$ and increases in $d_{1}$ if $d_{1}>0.75$. Second, $q_{1 \alpha A}<q_{2 \alpha A}$ and $q_{1 \gamma A}>q_{2 \gamma A}$ are always satisfied if $d_{1}>d_{2}$, despite the value of $\alpha$. Third, the opposite result can also be drawn for the market shares of platform 2 .

For the comparative statistics of the equilibrium profits, with respect to $\alpha$ and $d_{1}$, it can be observed that $\pi_{k}, \pi_{k A}$ and $\pi_{k B}$ are not monotonous functions, such as in the scenario when $\alpha=0$.

\subsection{Scenario $3: y=0$}

In this scenario, when $\gamma=0$, this indicates that $\alpha+\beta=1$, showing that the price discrimination strategy to partial agent $A$, whose transaction time exceeds the threshold, is only being executed by platform 2 , while platform 1 chooses not to use any price discrimination strategy. Here we address the issue of whether or not it is more beneficial to use of a price discrimination strategy.

Proposition3. Given $\gamma=0$, the equilibrium benchmark prices for each group of agents made by platform $k$ are given as follows:

$$
\begin{array}{cc}
P_{1 A}=(t-\theta)\left(1-\frac{2 \alpha \beta d_{2}^{2}}{\Lambda}\right) & P_{1 B}=(t-\theta)\left(1+\frac{2 \alpha \beta d_{2}^{2} \theta}{t \Lambda}\right) \\
P_{2 A}=(t-\theta) \frac{3\left(1-\beta d_{2}\right)}{\Lambda} & P_{2 B}=(t-\theta)\left(1+\frac{4 \alpha \beta d_{2}^{2} \theta}{t \Lambda}\right)
\end{array}
$$

the equilibrium market shares are:

$$
\begin{array}{ll}
q_{1 A}=\frac{1}{2}-\frac{\alpha \beta d_{2}^{2}(t-\theta)}{t \Lambda} & q_{1 B}=\frac{1}{2} \\
q_{2 A}=\frac{1}{2}+\frac{\alpha \beta d_{2}^{2}(t-\theta)}{t \Lambda} & q_{2 B}=\frac{1}{2}
\end{array}
$$

and the profit of each platform is:

$$
\pi_{1}=(t-\theta)\left[1-\frac{2 \alpha \beta d_{2}^{2}\left(\Lambda-\alpha \beta d_{2}^{2}\right)(t-\theta)}{t \Lambda^{2}}\right] \quad \pi_{2}=(t-\theta)\left[1-\frac{\alpha \beta d_{2}^{2}\left(5 \Lambda-4 \alpha \beta d_{2}^{2}\right)(t-\theta)}{2 t \Lambda^{2}}\right]
$$

where $\Lambda=3\left(1-\beta d_{2}\right)^{2}+4 \alpha \beta d_{2}^{2}$.

The following observations can be drawn from Proposition 3:

1) $p_{2 A}<P_{1 A}<P_{2 A}$ and $P_{1 B}<P_{2 B}$.

11) Despite the value of $d_{2}, q_{1 A}<q_{2 A}$ and $q_{1 B}=q_{2 B}$.

12) $\pi_{1}>\pi_{2}$

The first observation indicates that platform 2 sets higher benchmark equilibrium prices than those of platform 1. However, the discriminative price for those whose transaction time exceeds the threshold in platform 2 is lower than the benchmark equilibrium price of platform 1 . Additionally, compared with the equilibrium prices in the case with no price discrimination, then $P_{2 A}>t-\theta, P_{k B}>t-\theta$ and $P_{1 A}<t-\theta, p_{2 A}<t-\theta$. This reveals that platform 2 first raises its equilibrium prices and then gives partial agent $A$ a discriminative price. Finally, all of the agents, with the exception of the partial agent $A$, have higher entrance prices imposed. The reason behind $P_{1 A}<t-\theta$ is the cross-externality which connects the two platforms together and sends competitive signals to the others. The second observation implies that the use of a price discrimination strategy by platform 2 in an effort to attract more agents $A$ is feasible. However, the two platforms have equal market shares in agent $B$ 's market, such as is seen in the case of $\alpha=0$ and $\beta=0$. Although platform 2 can increase their profits from agent $B$ 's market, it will not compensate for the loss due to the price discount in agent $A$ 's market. This 
results in the final profit for platform 2 being less than the profit for platform 1 . Thus, we conclude that platform 2 can only attract more agents if it carries out a partial price discrimination strategy when its competitor chooses not to follow any price discrimination strategy.

Particularly, if $\alpha=0$ and $\gamma=0$, platform 2 sets up a price discount strategy for all agents $A$ who participate, while platform 1 makes no price discrimination choice, then $P_{1 A}=P_{k B}=t-\theta, P_{2 A}=(t-$ $\theta) /\left(1-d_{2}\right)$ and $q_{k i}=0.5$ and $\pi_{k}=t-\theta$. The price discount for platform 2 is a fraudulent act, as it was in scenario 1 , where $\alpha=0$; both the platforms share equally the market shares and the profits alike.

Corollary 2. Based on Proposition 3, the following can be made:

1) $q_{2 \beta A}>q_{1 \beta A}$ and $q_{2 \alpha A}<q_{1 \alpha A}$.

13) $\pi 2 \mathrm{~A}<\pi_{1 A}$ and $\pi_{2 B}>\pi_{1 B}$.

14) If $\beta\left(1-d_{2}\right)>\alpha, \pi_{k A}$ and $\pi_{k}$ decreases with $\alpha$, while $\pi_{k B}$ and $\pi_{1}-\pi_{2}$ increase with $\alpha$.

15) $\pi_{k A}$ and $\pi_{k}$ are a decreasing function of $d_{2}$ while $\pi_{k B}$ and $\pi_{1}-\pi_{2}$ are an increasing function of $d_{2}$.

Proof. The conclusion of Corollary 2 can easily be determined from the following results.

$$
\begin{aligned}
& q_{1 \alpha A}-q_{2 \alpha A}=\frac{\alpha \beta d_{2}\left(3+\alpha d_{2}-3 d_{2}\right)(t-\theta)}{t \Lambda}>0, \quad q_{1 \beta A}-q_{2 \beta A}=-\frac{\alpha \beta d_{2}\left(3+\alpha d_{2}-d_{2}\right)(t-\theta)}{t \Delta}<0 \\
& \pi_{1 A}-\pi_{2 A}=\frac{\alpha \beta d_{2}^{2}\left(t^{2}-\theta^{2}\right)}{2 t \Lambda}>0, \pi_{1 B}-\pi_{2 B}=-\frac{\alpha \beta \theta d_{2}^{2}(t-\theta)}{t \Delta}<0, \text { and } \pi_{1}-\pi_{2}=\frac{\alpha \beta d_{2}^{2}(t-\theta)^{2}}{2 t \Lambda}>0 .
\end{aligned}
$$

The first result shows that more agents $A$ choose platform 2 when they face a discriminatory price imposed by only one platform. Combining this result with proposition 3(2), we can conclude that platform 1 is at a competitive disadvantage. The second result is same as Corollary 1(2). The third result implies that the profits are not monotonic functions. Given a fixed discount rate and $\alpha<\left(1-d_{2}\right) /\left(2-d_{2}\right)$, a larger $\alpha$ implies a larger $N_{2}$, and is bad for the two platforms, but worse for platform 2. The competitive disadvantage of platform 2 improves when $\alpha>\left(1-d_{2}\right) /\left(2-d_{2}\right)$, but its profit is still less than the profit of platform 1. This means that platform 2 is at a competitive advantage and fails to maximise their profits. The first part of the fourth result is similar to Corollary 1(4). The second part of the fourth result implies that a larger $d_{2}$ puts platform 2 at a competitive disadvantage to platform 1 . Therefore, choosing a smaller $d_{2}$ is an optimal strategy for platform 2 when its competitor chooses not to use a price discrimination strategy.

Additionally, the comparative statistics for the parameters of $\alpha$ and $d_{2}$ on the other equilibrium variables are presented in Table 2.

Table 2

Comparative statistics cs for the scenario where $y=0$

\begin{tabular}{|c|c|c|c|c|c|c|c|c|c|c|c|}
\hline & \multicolumn{9}{|c|}{$P$} & \multicolumn{1}{c|}{$q$} \\
\cline { 2 - 12 } & \multicolumn{1}{|c|}{ Platform 1 } & \multicolumn{3}{c|}{ Platform 2 } & \multicolumn{3}{c|}{ Platform 1 } & \multicolumn{3}{c|}{ Platform 2 } \\
\cline { 2 - 12 } & $P_{1 A}$ & $P_{1 B}$ & $P_{2 A}$ & $p_{2 A}$ & $P_{2 B}$ & $q_{1 \alpha A}$ & $q_{1 \beta A}$ & $q_{1 A}$ & $q_{2 \alpha A}$ & $q_{2 \beta A}$ & $q_{2 A}$ \\
\hline$\alpha$ & $\downarrow^{*}$ & $\uparrow^{*}$ & $\uparrow^{* *}$ & $\uparrow^{* *}$ & $\uparrow^{*}$ & $\uparrow$ & $\downarrow$ & $\downarrow^{*}$ & $\downarrow$ & $\uparrow$ & $\uparrow^{*}$ \\
\hline$d_{2}$ & $\downarrow$ & $\uparrow$ & $\uparrow^{* * *}$ & $\downarrow$ & $\uparrow$ & $\uparrow^{* * *}$ & $\downarrow$ & $\downarrow$ & $\downarrow^{* * * *}$ & $\uparrow$ & $\uparrow$ \\
\hline
\end{tabular}

Note: $\downarrow$ decrease; $\uparrow$ increase; - uncertainty * $\beta\left(1-d_{2}\right)>\alpha$; ** $4 d_{2}\left[\alpha-\beta\left(1-d_{2}\right)\right]>\Lambda$;

$* * * 8 \alpha d_{2}<\Lambda ; * * * * 3\left(1-\beta d_{2}\right)^{2}>4 \alpha d_{2}$

Similarly, the same numerical example is given to show other detailed findings, that is, $t=1.2$ and $\theta=0.5$, and the illusive results are shown in Figure 3 . 
Figure 3

Impacts of $\alpha$ (when $d_{2}=0.4$ ) or (when $\alpha=0.4$ ) on equilibrium prices, market shares and profits

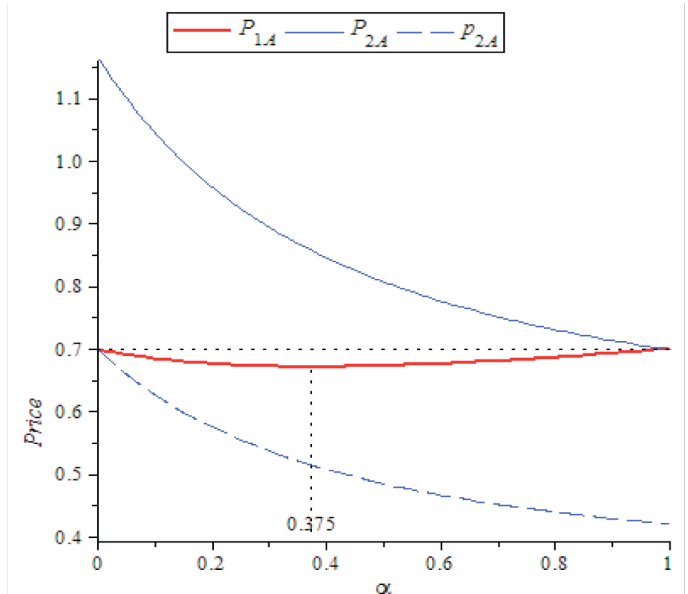

(a) Impact of $\alpha$ on equilibrium prices $\left(d_{2}=0.4\right)$

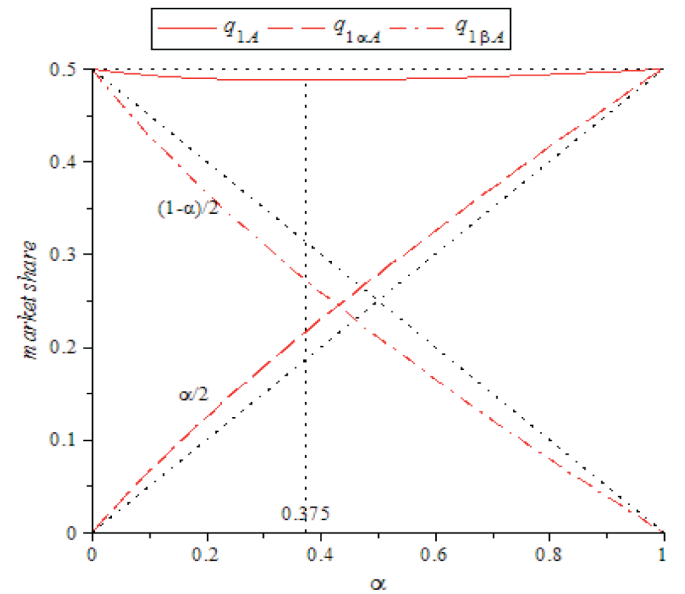

(b) Impact of $\alpha$ on market share $\left(d_{2}=0.4\right)$

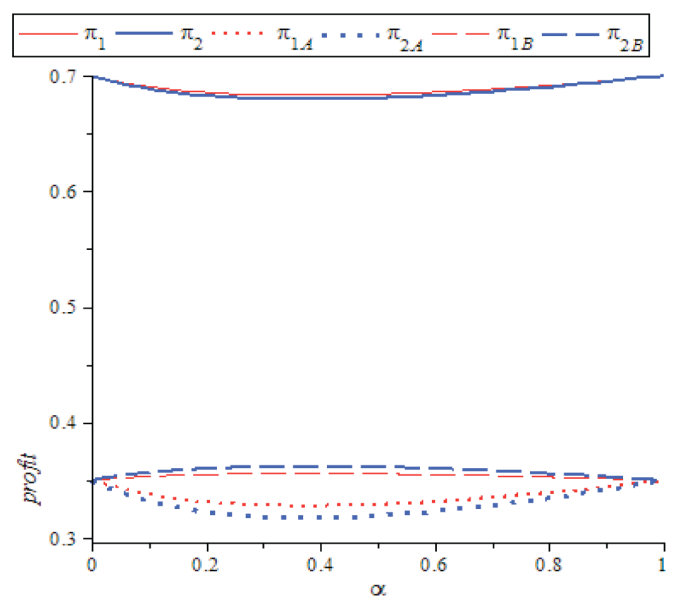

(c) Impact of $\alpha$ on profits $\left(d_{2}=0.4\right)$

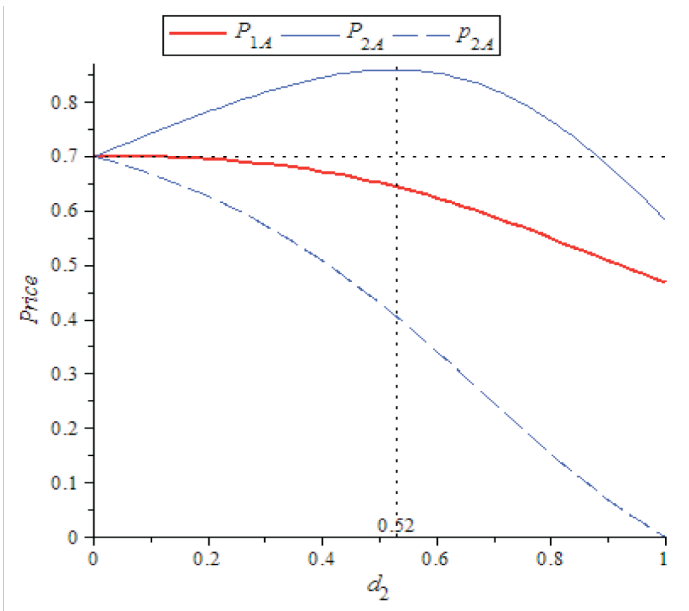

(d) Impact of $d_{2}$ on equilibrium prices $(\alpha=0.4)$

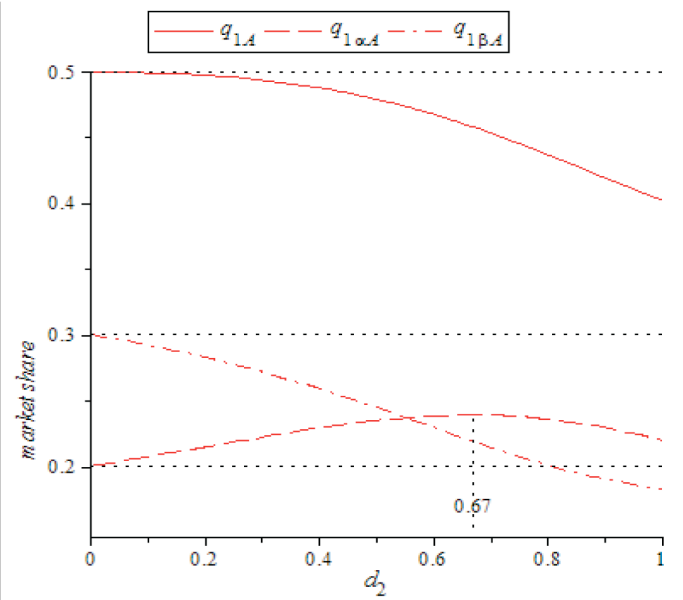

(e) Impact of $d_{2}$ on market share $(\alpha=0.4)$

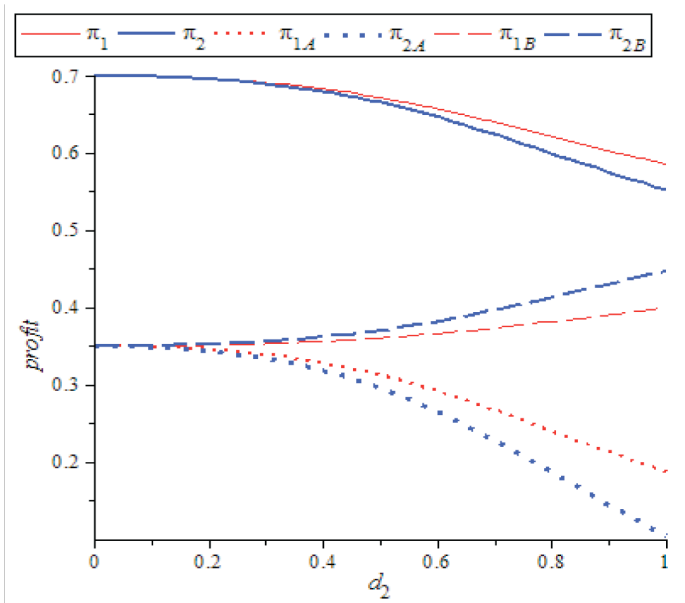

(f) Impact of $d_{2}$ on profits $(\alpha=0.4)$ 
For the comparative statistics of equilibrium prices, with respect to $\alpha$ and $d_{2}$, as shown in Figure 3(a) and Figure 3(d), the following observations can be made. First, $P_{2 A}$ and $p_{2 A}$ decrease in $\alpha$, but $P_{2 A}$ decreases in $d_{2}$ if $d_{2}>0.52$ and increases in $d_{2}$ if $d_{1}<0.52$; the rest of the variables accord with Table 2 . Second, $P_{2 A}-P_{1 A}$ increases in $\alpha$.

For the comparative statistics of equilibrium market shares of platform 1 in agent $A$ 's market, with respect to $\alpha$ and $d_{2}$, it can be observed that $q_{1 A}$ decreases in $\alpha$ if $\alpha<0.375$ and increases in $\alpha$ if $\alpha>0.375$, whereas $q_{1 \alpha A}$ increases in $d_{2}$ if $d_{2}<0.67$ and decreases in $d_{2}$ if $d_{2}>0.67$.

\subsection{Comparison of three scenarios}

This section compares the equilibrium solutions among the three scenarios in two-sided platforms with price discrimination. The analysis reveals the following:

A two-sided platform with a price discrimination strategy cannot simultaneously attract more agents and increase the profits. The profits are greater with fewer agents $A$ in platform 2 in scenarios 1 and 2, where $\alpha=0$ and $\beta=0$ (if $d_{1}>d_{2}$ ), The opposite is true in scenario 3 , where $\gamma=0$.

A lower price discrimination threshold does not ensure bigger market shares due to a non-monotonic function, as shown in Figure 1(b), Figure 2(b) and Figure 3(b), so are the total profits, as shown in Figure 1(c), Figure 2(c) and Figure 3(c). Platform 1 receives the biggest market share of agent $A$ when $\beta=0.375$ in scenario 1 where $\alpha=0$ and $\alpha=0.36$ in scenario 2 where $\beta=0$, and the smallest market share of agent $A$ when $\alpha=0.375$ in scenario 3 where $\gamma=0$.

A larger discount rate is bad for the profit of a platform, but good for its market share, as shown in Figure 2(f), Figure 3(f), Figure 2(e) and Figure 3(e). To a certain extent, this conclusion is also correct in scenario 1 , where $\alpha=0$, because $\pi_{2}>\pi_{1}$ and $q_{1 A}>q_{2 A}$ always hold despite the relation between $d_{2}$ and $d_{1}$. In other words, a larger discount rate is an effective way of overcoming the chicken and egg problem.

The best response strategy for a platform aiming at maximising profit is also for it to remain intact when its opponent chooses a price discrimination strategy; otherwise it receives a smaller profit, despite what the discount rates are. In addition, the equilibrium profits are less than those without a price discrimination strategy.

\section{Concluding remarks}

This paper analyses a price discrimination strategy model in duopolistic single-homing two-sided platforms; a research area that has previously received little attention. Theoretically, we extend a recent duopolistic model proposed initially by Rochet and Tirole (2006), Armstrong (2006a) and Liu and Serfes (2013). We incorporate a price discrimination strategy into their models. Using the feedback solutions from dynamic game theory, the optimal prices, market shares and profits for three different scenarios are obtained and the comparative statistics for the different factors based on different aims are presented.

The analysis clearly indicates that no agent should trust a full price discrimination strategy in a two-sided platform. This would also result in the failure of the platform to attract more agents. Agents whose transaction times exceed the price discrimination threshold are able to reap the benefits from price discrimination made by a two-sided platform, but the rest are at a disadvantage because they are charged high benchmark equilibrium prices. Two-sided platforms with a price discrimination strategy cannot simultaneously attract more agents and increase their profits. The best response strategy for a platform aiming at maximising their profit is therefore to maintain their price discrimination strategy when their opponent chooses to use the same strategy, otherwise they will receive a smaller profit despite what the discount rates are. A low price discrimination threshold, a situation in which more agents are enjoying the price discrimination strategy, cannot ensure bigger market shares because of the non-monotonic function. However, a large discount rate is bad for a platform from the perspective of both the market share and the profit. 
The overall importance and the managerial implications of our results are somewhat limited owing to the simplification of the assumptions in the model. Future research should be extended to encompass a price discrimination strategy on both sides of a two-sided platform. Using the visa card as an example, users and merchants are simultaneously confronted with the issue of price discrimination imposed by the visa card. However, the foundation is different. The former is usually the total value of transactions, while the latter is typically the transaction times. Future research should also focus on the long-term perspective, which may address the issue of why the price discrimination strategy cannot be executed for a long period. Further, future efforts will determine whether it is a solution to the chicken and egg problem or an effective strategy for gaining an advantageous position in competition once the dynamic growth path of a two-sided market is described.

\section{Acknowledgement}

The authors alone are responsible for the remaining errors. Additionally, this work is supported in part by the Natural Science Foundation of China (71102173), the China Postdoctoral Science Foundation Funded Project (2013M530890) and the China Postdoctoral Science Special Foundation (2014T70232) and Program for the Outstanding Innovative Teams of Higher Learning Institutions of Shanxi (2015052005) and the Scientific Research Foundation for the Returned Overseas Chinese Scholars, Shanxi (2015-024).

\section{References}

ARMSTRONG, M. 2006a. Competition in two-sided markets. RAND Journal of Economics, 37(3):668-691.

ARMSTRONG, M. 2006b. Recent developments in the economics of price discrimination. Chapter 4 in Advances in Economics and Econometrics. PP.97-141. Cambridge University Press.

ARMSTRONG, M. \& WRIGHT, J. 2007. Two-sided markets, competitive bottlenecks and exclusive contracts. Economic Theory, 32(2):353-380.

BAXTER, W.F. 1983. Bank exchange of transactional paper: Legal and economic perspectives. Journal of Law and Economics, 26(3):541-588.

CAILlAUD, B. \& JULLIEN, B. 2003. Chicken \& egg: Competition among intermediation service providers. RAND Journal of Economics, 34(2):309-328.

CHAKRAVORTI, S. \& ROSON, R. 2006. Platform competition in two-sided markets: The case of payment networks. Review of Network Economics, 5(1):118-142.

CHEN, K. \& TSE, E. 2007. Dynamic platform competition in two-sided markets. Working paper, Stanford University. Available at: < http://papers.ssrn.com/sol3/papers.cfm?abstract_id=1095124 > [accessed February 2007].

DAVID, P.A. 1985. Clio and the economics of QWERTY. American Economic Review, 75(2):332-336.

DOGANOGLU, T. \& WRIGHT, J. 2006. Multi-homing and compatibility. International Journal of Organization, 24(1):45-67.

ECONOMIDES, N. 2008. "Net neutrality," non-discrimination and digital distribution of content through the internet. I/S: A Journal of Law and Policy for the Information Society, 4(2):209-233.

ECONOMIDES, N. \& KATSAMAKAS, E. 2006. Two-sided competition of proprietary vs. open source technology platforms and the implications for the software industry. Management Science, 52(7):1057-1071. ERIKSSON, K., SJÖSTRAND, J. \& STRIMLING, P. 2008. Asymmetric equilibria in dynamic two-sided matching markets with independent preferences. International Journal of Game Theory, 36(3):421-440. FARRELL, J. \& SALONER, G. 1985. Standardization, compatibility and innovation. RAND Journal of Economics, 16(1):70-83.

GABSZEWICZ, J. \& WAUTHY, X. 2004. Two-sided markets and price competition with multi-homing. Working paper, Université Catholique de Louvain. Available at: http://papers.ssrn.com/sol3/papers.cfm? abstract_id=975897 [accessed May 2004].

GIL, R. \& RIERA-CRICHTON, D. 2011. Price discrimination and competition in two-sided markets: Evidence from the Spanish local TV industry. Working Paper, Johns Hopkins Carey Business School. Available at: < http://papers.ssrn.com/sol3/papers.cfm?abstract_id=1873231 > [accessed January 2011]. 
GUTHRIE, G. \& WRIGHT, J. 2007. Competing payment schemes. The Journal of Industrial Economics, 55(1):37-67.

HAGIU, A. \& LEE, R.S. 2011. Exclusivity and control. Journal of Economics \& Management Strategy, 20(3):679-708

HAGIU, A. \& JULLIEN, B. 2007. Designing a two-sided platform: When to increase search costs? Working paper. Available at: <http://ideas.repec.org/p/ide/wpaper/7369.html $>$ [accessed August 2007].

HAGIU, A. \& SPULBER, D. 2012. First-party content and coordination in two-sided markets. Management Science, 59(4):933-949.

KAISER, U. \& WRIGHT, J. 2005. Price structure in two-sided markets: Evidence from the magazine industry. International Journal of Industrial Organization, 24(1):1-28.

KATZ, M.L. \& SHAPIRO, C. 1985. Network externalities, competition, and compatibility. American Economic Review, 75(3):424-440.

LIU, Q.H. \& SERFES, K. 2013. Price discrimination in two-sided markets. Journal of Economics \& Management Strategy, 22(4):768-786.

LOERTSCHER, S. 2007. Horizontally differentiated market makers. Journal of Economics \& Management Strategy, 16(4):793-825.

NOCKE, V. \& PEITZ, M. 2007. Platform ownership. Journal of the European Economic Association, 5(6):1130-1160.

PIGOU, A.C. 1920. The economics of welfare. London: Macmillan.

REISINGER, M. 2014. Two-part tariff competition between two-sided platforms. European Economic Review. 68:168-180.

ROCHET, C. \& TIROLE, J. 2003. Platform competition in two-sided markets. Journal of the European Economic Association, 4(6):990-1029.

ROCHET, C. \& TIROLE, J. 2004. Two-sided markets: An overview. Working Paper. Available at: $<$ http://faculty.haas.berkeley.edu/HERMALIN/rochet_tirole.pdf $>$ [accessed March 2004].

ROCHET, J.C. \& TIROLE, J. 2006. Externalities and regulation in card payment systems. Review of Network Economics, 5(1):1-14.

ROSON, R. 2005. Platform competition with endogenous multi-homing. Working Paper. Available at: $<$ http://papers.ssrn.com/Sol3/papers.cfm?abstract_id=657901 $>$ [accessed January 2005].

RUST, J. \& HALL, G. 2003. Middlemen \& market makers: A theory of competitive exchange. Journal of Political Economy, 111(2):353-403.

RYSMAN, M. 2004. Competition between networks: A study of the market for yellow pages. Review of Economic Studies, 71(2):483-512.

SCHIFF, A. 2003. Open and closed systems of two-sided networks. Information Economics of Policy, 15(4):425-442.

SCHMALENSEE, R. \& EVANS, D.S. 2007. Industrial organization of markets with two-sided platforms. Competition policy international, 3(1):151-179.

SPULBER, D.F. 1996. Market macrostructure and intermediate. Journal of Economic Perspectives, 63(10):135-152.

STOLE, L.A. 2003. Price discrimination and imperfect competition. The Handbook of Industrial Organization (III).

SUN, M. \& TSE, E. 2007. When does the winner take all in two-sided markets? Review of Network Economics, 6(1):16-40.

WEISMAN, L.D. \& KULICK, B.R. 2010. Price discrimination, two-sided markets, and net neutrality regulation. Working paper. Available at: $<$ http://papers.ssrn.com/sol3/papers.cfm?abstract id $=1582972>$ [accessed March 2010].

WRIGHT, J. 2004. One-sided logic in two-sided markets. Review of Network Economics, 3(1):44-64. 